5 Crile G Jr. Management of breast cancer: limited mastectomy. JAMA 1974;230:95-8.

6 National Center for Health Statistics. International classification of diseases, 8th revision. Rockville, MD: Public Health Service, 1967. (Public Health Service publication No 1693.)

7 National Center for Health Statistics. International classification of diseases, 9th revision: clinical modification. Ann Arbor, Michigan: Commission on Professional and Hospital Activities, 1978.

8 National Center for Health Statistics. Development of the design of the NCHS hospital discharge survey. Rockville, MD: National Center for Health Statistics, 1970. (Vital and Health Statistics Series 2, No 39.

9 US Department of Commerce, Bureau of the Census. Annual reports 1970-80. Washington, DC: US Department of Commerce. (Current population estimates and projections, series P-25.)

10 National Center for Health Statistics. Inpatient utilization of short-stay hospitals by diagnosis: United States 1980. Hyattsville, MD: National Center for Health Statistics, 1983. (Vital and Health Statistics Series 13, No 74.)

11 Snedecor GW, Cochran WG. Statistical methods. 7th ed. Ames, Iowa: Iowa State University Press, 1980.

12 Office of Population Censuses and Surveys. Hospital inpatient enquiry: summany tables 1979. London, HMSO, 1982. (Series MB4, No 13.)

13 OPCS. Classification of surgical operations, 3rd revision. London: HMSO, 1975

13 OPCS. Classification of surgical operations, 3rd revision. London:

15 Shapiro S, Strax P, Venet L. Periodic breast cancer screening in reducing mortality from breast cancer. FAMA 1971;215:1777-85.

16 Tabar L, Fagerberg CJG, Gad A, et al. Reduction in mortality from breast cancer after mass screening with mammography. Randomized trial from the Breast Cancer Screening Working Group of the Swedish National Board of Health and Welfare. Lancet 1985;i:829-32.

17 Pollack ES, Horm JW. Trends in cancer incidence and mortality in the United States, 1969-76. Journal of the National Cancer Institute 1980;64:1091-103.

18 Devesa SS, Pollack ES, Young JL Jr. Assessing the validity of observed cancer incidence trends. Am f Epidemiol 1984;119:274-91.

19 Beahrs OH, Shapiro S, Smart C, et al. Report of the working group to review the National Cancer Institute-American Cancer Society Breast Cancer Detection Demonstration Projects. Foumal of the National Cancer Institute 1979;62:640-709.

20 Byrd BF. ACS/NCI Breast Cancer Detection Demonstration Projects. Cancer 1980;46: 1084-6.
21 Kane R. Organizing to improve the management of a disease: an overview of the breast cancer networks. In: Engstrom PF, Anderson PN, Mortemor LE, eds. Advances in cancer control: research and development. New York: Alan R Liss, 1983.

22 Black MM, Leis HP, Jr, Kwan CS. The breast cancer controversy: a natural experiment. JAMA 1977;237:970-1.

23 Kolata G. Research news: debate over cancer screening. Science 1985;229:636-7.

24 Bailar JC. Mammography: a contrary view. Ann Intern Med 1976;84:77-84.

25 Wilson RE, Donegan WL, Mettlin C, et al. The 1982 national survey of carcinoma of the breast in the United States by the American College of Surgeons. Surg Gynecol Obstet 1984;159:309-18.

26 Fisher B. Reappraisal of breast biopsy prompted by the use of lumpectomy: surgical strategy. JAMA $1985 ; 253: 3585-8$.

27 Kleinman JC, Machlin SR, Madans J, et al. Changing practice in the surgical treatment of breast cancer. Med Care 1983;21:1232-42.

$28 \mathrm{MacWhirter} R$. The value of simple mastectomy and radiotherapy in the treatment of cancer of the breast. Br f Radiol 1948;21:599-610.

Mueller CB. Surgery for breast cancer: less may be as good as more. N Engl f Med 1985;312:712-4.

30 Shapiro S. Evidence on screening for breast cancer from a randomized trial. Cancer 1977;39: $2772-82$

31 Anonymous. Screening for breast cancer. Lancet 1984;i:1217-8.

32 Wennberg JE, Gittelsohn AM. A small area approach to the analysis of health systems performance. Washington, DC: Government Printing Office, 1980. (DHHS publication No(HRA) 80-14012.) 33 Commission on Professional and Hospital Activities. Hospital morality, PAS hospitals, United States 1972-73. Ann Arbor, Michigan: CPHA, 1975.

34 Waterhouse J, Muir C, Correa P, Powell J. Cancer incidence in five continents. Vol III. Lyons: International Agency for Research in Cancer, 1976. (Publication No 15.)

35 Gray GE, Pike MC, Henderson BE. Breast cancer incidence and mortality rates in different countries in relation to known risk factors and dietary practices. $\mathrm{Br} \mathcal{F}$ Cancer 1979;39:1-7.

$36 \mathrm{McPherson} \mathrm{K,} \mathrm{Fox} \mathrm{MS.} \mathrm{Treatment} \mathrm{of} \mathrm{breast} \mathrm{cancer.} \mathrm{In:} \mathrm{Bunker} \mathrm{JP,} \mathrm{Barnes} \mathrm{BA,} \mathrm{Mosteller} \mathrm{F,} \mathrm{eds.}$ Costs, risks, and benefits of surgery. New York: Oxford University Press, 1977.

(Accepled 3 March 1986)

\title{
Quality of life after myocardial infarction: effect of long term metoprolol on mortality and morbidity
}

\author{
GUNNAR OLSSON, JACOBUS LUBSEN, GERRIT-ANNE VAN ES, NINA REHNQVIST
}

\section{Abstract}

A double blind randomised study of 154 patients with myocardial infarction assigned to metoprolol (100 $\mathrm{mg}$ twice daily) and 147 assigned to placebo compared the effects of treatment in relation to health state over three years. Health state was evaluated by a new method based on the average number of days spent in each of seven mutually exclusive categories of health. The scale took into account death, history of serious complications, functional state, and side effects of treatment.

Of the maximum attainable 1095 days alive during the three years patients given metoprolol attained 992 days and those given placebo 964 days. During the period alive the metoprolol treated group spent an average of $\mathbf{2 7 8}$ days in an optimal functional state as compared with 176 days for the placebo treated group. This included 221 and 156 days respectively in a completely asymptomatic state (that is, without either cardiac symptoms or side effects of treatment). The time spent with a serious non-fatal complication was shortened by $\mathbf{5 6}$ days in the metoprolol group. The overall differences between the groups were statistically significant $(p=0.03)$.

Aside from bringing an improved quality of life after myocardial infarction, metoprolol may add up to one month to life expectancy for three years of treatment.

Department of Medicine, Karolinska Institutet, Danderyd Hospital, S-182 88 Danderyd, Sweden

GUNNAR OLSSON, MD, senior registrar

NINA REHNQVIST, MD, associate professor

Clinical Epidemiology Unit, Department of Cardiology (Thoraxcenter),

Erasmus University, Rotterdam, Netherlands

JACOBUS LUBSEN, MD, professor

GERRIT-ANNE VAN ES, MS, master of science and engineering

Correspondence and requests for reprints to: Dr Olsson.

\section{Introduction}

Clinical trials have shown the benefits of $\beta$ adrenoceptor blockade after acute myocardial infarction. ${ }^{1-4}$ Nevertheless, the possibilities of negative side effects and the cost of treatment have led to doubts about the widespread use of these drugs. In clinical trials total mortality on the one hand and various non-fatal events, including side effects, on the other have been reported as separate entities for the groups compared. Hence it is difficult to determine exactly what effect the treatment has had on the quality of life and course of the disease as compared with placebo.

In clinical decision analysis the concept of life expectancy is used to express the value (utility) of the options considered. ${ }^{5}$ Quality adjustment of life expectancy has been proposed to take morbidity and wellbeing into account. ${ }^{6}$ We have applied these concepts to data from the Stockholm metoprolol trial, which was designed to evaluate the effect of long term metoprolol treatment on mortality and morbidity after acute myocardial infarction. ${ }^{4}$

\section{Patients and methods}

Full details of the study have been reported elsewhere. ${ }^{4}$ Briefly, patients under 70 surviving an acute myocardial infarction, in sinus rhythm and without bundle branch block, and without contraindications to $\beta$ adrenoceptor blockade were included. Myocardial infarction was diagnosed if the patient had at least two of the following: severe chest pain lasting more than 15 minutes; a typical enzyme pattern; typical changes in the electrocardiogram.

Between May 1976 and December 1980,301 patients $66 \%$ of the total population under 70 living in the hospital catchment area who had survived myocardial infarction) were entered into the study. All gave verbal informed consent. One to two weeks after the acute event-that is, in the phase after treatment in the coronary care unit-patients were stratified according to type of ventricular arrhythmias, size of infarct (estimated enzymatically), and age. ${ }^{4}$ Thereafter they were allocated to double blind treatment with metoprolol $100 \mathrm{mg}$ twice daily $(n=154)$ or matching placebo $(n=147)$ for three years. The protocol was approved by the local ethical committee 
During the study the following general treatment regimens were adopted. Patients who developed troublesome symptoms thought to be due to side effects of the study treatment initially had the dose halved without breaking the code. If symptoms persisted treatment was withdrawn, also without breaking the code. Angina pectoris was treated with long acting nitrates and calcium antagonists. If this was insufficient the study treatment was withdrawn and open $\beta$ blockade given. If this also failed the patient was referred for coronary artery bypass surgery. Only symptomatic ventricular arrhythmias were treated. Anticoagulants and antiplatelet drugs were not regularly used. All data presented here are based on the initial drug allocation - that is, "intention to treat"-except where cost of the $\beta$ blocker treatment is analysed.

During the three year study period patients were followed up in the outpatient clinic (by GO and NR) at one, three, and six months and thereafter every six months. At each visit the patient's functional state was evaluated according to the New York Heart Association's classification? (class I, ordinary physical activity does not cause cardiac symptoms, such as undue fatigue, palpitations, anginal pain, or dyspnoea; class II, ordinary physical activity results in cardiac symptoms; class III, less than ordinary physical activity causes cardiac symptoms; class IV, cardiac symptoms are present at rest and any physical activity increases discomfort) and treatment with digitalis, diuretics, and antiarrhythmic drugs noted. Costs of $\beta$ blocker treatment were adjusted to 1985 prices and expressed in US dollars.

Patients were actively asked about possible side effects of treatment (cardiopulmonary, gastrointestinal, central nervous system, allergic, or others) using a special questionnaire (details obtainable from GO). Study treatment was withdrawn after three years. ${ }^{8}$ Codes were not broken until the patients had completed the three years of follow up.

Data on mortality and cardiac morbidity, including admission for reinfarction, angina pectoris, heart failure, arrhythmias, and coronary artery bypass surgery, were recorded together with dates of the events. Other atherosclerotic complications recorded included cerebrovascular events and peripheral arterial insufficiency requiring amputation of part of the leg for gangrene. Cerebrovascular events were defined as acute onset of transient or persistent hemiplegia or loss of sensory function.

At each follow up visit patients were ranked as follows according to seven mutually exclusive categories of health state (categories 1 and 7 taken as worst and best, respectively): (1) dead; (2) alive but had sustained non-fatal atherosclerotic complication (reinfarction, cerebrovascular event, coronary artery bypass surgery, leg amputation); (3) alive and in functional class IV without atherosclerotic complication); (4) as (3) but in functional class III; (5) as (3) but in functional class II; (6) as (3) but in functional class I with suspected side effects of study treatment; (7) as (6) but without suspected side effects of study treatment.

Mean survival time for each treatment group was calculated as the mean time elapsed between entry to the study and death or end of follow up (three years). Mean survival time was further subdivided into the mean time spent in each of health categories 2 to 7 . This was based on the exact date of transition to category 2-that is, occurrence of a non-fatal event definitive for this category. Transition among categories 3 to 7 was assumed to have occurred halfway between two subsequent follow up visits. If the patient was in the same category at two subsequent visits we assumed that the patien had been in that category for the entire interval between the visits. Patients in categories 3 to 7 at the first follow up visit (one month) were assumed also to be in this category at discharge from hospital. Patients who died (category 1) or had a non-fatal atherosclerotic complication (category 2) before the first

TABLE I-Baseline characteristics of patients. Except where stated otherwise figures are numbers (percentages) of patients

\begin{tabular}{|c|c|c|}
\hline & $\begin{array}{l}\text { Placebo group } \\
\quad(n=147)\end{array}$ & $\begin{array}{l}\text { Metoprolol group } \\
(\mathrm{n}=154)\end{array}$ \\
\hline Mean age in years $(\mathrm{SD})$ & $59 \cdot 2(7 \cdot 2)$ & $60 \cdot 1(6 \cdot 7)$ \\
\hline Men & $122(83)$ & $120(78)$ \\
\hline Previous myocardial infarction & $29(20)$ & $32(21)$ \\
\hline Cerebrovascular event before myocardial infarction & $4(3)$ & $8(5)$ \\
\hline Q Wave infarction & $106(72)$ & $116(75)$ \\
\hline \multicolumn{3}{|l|}{ Site of infarction: } \\
\hline Anterior & $75(51)$ & $68(44)$ \\
\hline Inferior & $46(31)$ & $58(38)$ \\
\hline Unknown & $26(18)$ & $28(18)$ \\
\hline \multicolumn{3}{|l|}{ Mean (SD) peak of thermostable fraction of lactate } \\
\hline Ventricular fibrillation in coronary care unit & $4(3)$ & $5(3)$ \\
\hline Rales in coronary care unit & $98(67)$ & $100(65)$ \\
\hline $\begin{array}{l}\text { Systolic blood pressure }<90 \mathrm{~mm} \mathrm{Hg} \text { in coronary care } \\
\text { unit }\end{array}$ & $15(10)$ & $15(10)$ \\
\hline $\begin{array}{l}\text { Complex premature ventricular complexes at } \\
\text { randomisation }\end{array}$ & $49(33)$ & $59(38)$ \\
\hline \multicolumn{3}{|l|}{ Treatment at discharge: } \\
\hline Digitalis & $35(24)$ & $35(23)$ \\
\hline Diuretics & $70(48)$ & $65(42)$ \\
\hline Antiarrhythmic agents & $9(6)$ & $9(6)$ \\
\hline
\end{tabular}

visit were assumed to be in category 3 at discharge. The health state rank of a patient who missed a visit was interpolated from ranks immediately before and after the missed visit. The proportions of time spent in the different health state categories were used in comparing the two treatment groups to obtain a rough estimate of the effect of treatment on the quality of life.

As an approximate overall test of the significance of difference between the two groups health state rankings were subjected to an analysis of variance of repeated measurements (Biomedical Computer Programs, program 2V). ${ }^{9} \overline{\mathrm{J}}$

\section{Results}

One hundred and forty seven patients were allocated to receive placebo and 154 to receive metoprolol. No patient was lost to follow up with respect? to mortality and cardiac morbidity. Altogether 37 visits were missed during follow up $(1.5 \%$ of the total). Table I shows the baseline characteristics of patients in the two groups.

Twenty four $(16 \%)$ of the placebo treated and $27(18 \%)$ of the metoprolo treated patients were withdrawn during the first year. Corresponding figuresi for the second and third years were $5(3 \%) v 6(4 \%)$ and $6(4 \%) v 5(3 \%)$. Withdrawal due to uncontrolled angina pectoris was significantly moreo common in the placebo group and withdrawal due to heart failure more common in the metoprolol group. ${ }^{4}$ The mean cost of $\beta$ blockade per patient $\vec{\omega}$ was $\$ 22$ and $\$ 259$ in the placebo-that is, patients withdrawn due to angina? pectoris and treated with open $\beta$ blockade-and metoprolol groups,, 3 respectively, during the three years.

Digitalis was given to roughly a third and diuretics to about half of alfo patients throughout follow up. Class 1 antiarrhythmic drugs were given long term to one of the placebo treated and three of the metoprolol treatedy patients. There were no differences in general treatment between the two groups.

Table II summarises the major events that occurred during follow up ande the figure the change in health state categories in each treatment group.

TABLE II-Major events during three years of follow up. Figures are number (percentages) of patients

\begin{tabular}{lcc}
\hline & $\begin{array}{c}\text { Placebo group } \\
(\mathbf{n}=147)\end{array}$ & $\begin{array}{c}\text { Metoprolol group } \\
(\mathbf{n}=154)\end{array}$ \\
\hline Total deaths & $31(21)$ & $25(16)$ \\
Cardiac death & $29(20)$ & $20(13)$ \\
Non-fatal reinfarction & $31(21)^{\star}$ & $18(12)$ \\
Coronary artery bypass surgery & $9(6)$ & $3(2)$ \\
Cerebrovascular event & $11(7)^{\star}$ & $3(2)$ \\
Leg amputation & $3(2)$ & 0 \\
Death or any atherosclerotic event & $64(44)^{\star \star}$ & $42(27)$ \\
\hline${ }^{\star} \mathbf{p}<0.05 . \quad{ }^{\star \star} \mathrm{p}<0 \cdot 01$. & &
\end{tabular}

${ }^{\star} \mathrm{p}<0.05 . \quad{ }^{\star \star} \mathrm{p}<0.01$

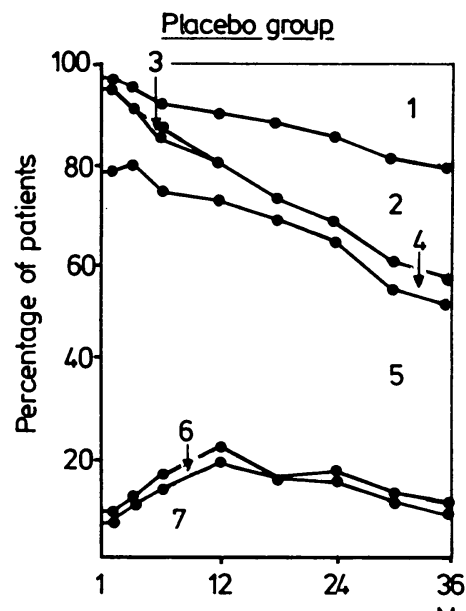

Metoprolol group

Proportions of patients in each health category (see text) as function of follow up time $(p=0 \cdot 03)$. (Lesser data omitted for clarity.)

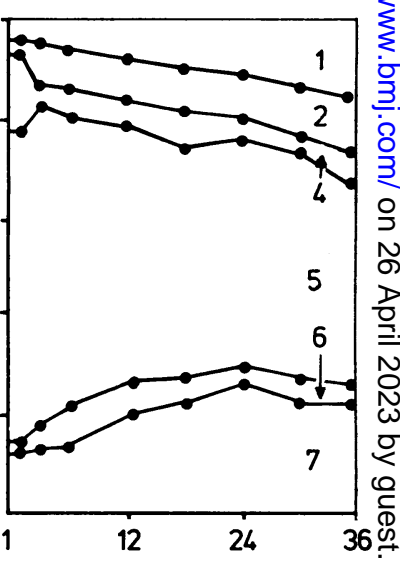

(p.03). (Lesser data omitted for clarity.)

Table III shows the mean survival times up to three years in the two groups. Of the maximum attainable 1095 days, the metoprolol treated patients survived an average of 992 days as compared with 964 days in the placebo group. Subdividing mean survival time into time spent in eacho health state category showed that the metoprolol treated patients spent $5 \lessdot$ 
TABLE III-Mean number of days spent in different health categories during maximum attainable 1095 days of follow up. Figures in parentheses in categories 2-7 are percentages of time patients remained alive in those categories

\begin{tabular}{lcc}
\hline Category & Placebo group & Metoprolol group \\
\hline 1 (Dead) & 131 & 103 \\
2 (Atherosclerotic complication) & $151(16)$ & $95(10)$ \\
3 (NYHA class IV without atherosclerotic complication) & $1(<1)$ & 0 \\
4 (NYHA class III without atherosclerotic complication) & $90(9)$ & $78(8)$ \\
5 (NYHA class II without atherosclerotic complication) & $546(57)$ & $541(55)$ \\
6 (NYHA class I and side effects, without atherosclerotic & $20(2)$ & $57(6)$ \\
$\begin{array}{l}\quad \text { complication) } \\
7 \text { (NYHA class I without side effects or atherosclerotic } \\
\text { complication) }\end{array}$ & $156(16)$ & $221(22)$ \\
\hline $2-7$ (survival time) & $964(100)$ & $992(100)$
\end{tabular}

NYHA $=$ New York Heart Association.

Overall difference between groups was significant $(p=0 \cdot 03)$.

days less with a non-fatal atherosclerotic complication and 65 days more in category 7 (New York Heart Association functional class I without suspected side effects of study treatment) compared with the placebo treated patients. Suspected side effects in category 6 were mild and without serious complications. The overall difference between the two groups was statistically significant at the $3 \%$ level.

\section{Discussion}

Results of clinical trials with long term follow up are usually reported as $(a)$ a survival curve and $(b)$ relative frequencies of various non-fatal events considered independently. From such data it is difficult to tell exactly what effect the treatment has had on the patients' health state over time. Though death is a uniquely defined state, different non-fatal events may occur in combination and affect health state in a way that cannot be defined from such presentation.

In this analysis of a previous study ${ }^{4}$ we have attempted to present a more interpretable picture of what the treatment at issue-metoprolol given for three years after myocardial infarction-actually achieved compared with placebo. Our approach is based on concepts derived from clinical decision analysis, which to our knowledge has not been applied in clinical trials. The approach uses a health state scale with mutually exclusive categories and estimation of the average time spent in each category from repeated follow up examinations. The objectives of treatment after myocardial infarction are to prolong survival, prevent serious nonfatal atherosclerotic complications, and banish cardiac symptoms. These factors reflect functional states and are a rough measure of the quality of life. Computationally, the estimated average time spent in each health category is simple to obtain using these assumptions. So far as we know there is no theoretical optimal approach to interval estimation and significance testing, so we used a less optimal test. Nevertheless, when only death or atherosclerotic complications (that is, categories 1 and 2) versus no such events (categories 3 to 7 ) were analysed the difference was still significant $\left(\mathrm{p}<0.01 ; \chi^{2}\right.$ test; table II).

Our results suggest that patients treated with metoprolol after an acute myocardial infarction may gain an average of 28 days of life for each three years of treatment (table III). Perhaps the most important additional finding was that metoprolol added an average of 102 days of optimal functional capacity at the cost of some days of suspected side effects of $\beta$ blockade (table III). The time spent in a completely asymptomatic state was also prolonged (from 156 to 221 days) by metoprolol. Furthermore, the reduction from an average of 151 to 95 days of being seriously ill after a severe non-fatal complication is also important. In our series this reflected both a reduction of events and a postponing of these events. In this context we have included coronary artery bypass surgery as a major complication, since in Sweden this procedure is used only in serious cases of symptomatic coronary artery disease and represents an important life event, though the patient may have fewer symptoms afterwards.

It may be argued that for an individual patient the distinction among some of the health state categories is arbitrary. We believe that it is nevertheless useful to determine health state ranking at regular intervals during follow up to derive the average time spent in each category as a basis for comparing different treatments. Plainly, however, differences can be attributed to treatment only if health state ranking is independent of treatment-that is, determined double blind-as in this study.

Benefits of new treatments have to be presented to and discussed with patients and health authorities alike. We think that the form used to present data here is an understandable basis for such communication. At the same time the data may be used directly as input for calculations of cost effectiveness, since the average time spent in each category may be related to community costs and benefits, provided that an appropriate scale is chosen. In this context various scales can be envisaged, expressing different aspects of the disease problem at hand. In this analysis we confined ourselves to functional cardiac aspects.

In conclusion, by using a new method, including health scale ranking with mutually exclusive categories, for evaluating a long term trial of metoprolol after acute myocardial infarction we have shown that the treatment resulted in a prolongation of both survival and time spent completely asymptomatic as well as in an optimal functional state, whereas less time was spent disabled after a serious non-fatal atherosclerotic complication. The method used for evaluating morbidity and mortality seems useful for presentation of data from long term intervention trials to obtain a clear view of the actual effects on health state of the treatment studied.

This study was supported by grants from the Swedish National Association against Chest and Heart Disease and A B Hässle, Mölndal, Sweden.

\section{References}

1 Norwegian Multicenter Study Group. Timolol-induced reduction in mortality and reinfarction in patients surviving acute myocardial infarction. N Engl f Med 1981;304:801-7.

2 Hjalmarson $\AA$, Elmfeldt D, Herlitz J, et al. Effect on mortality of metoprolol in acute myocardial infarction. A double-blind randomised trial. Lancet 1981;ii:823-7.

3 Beta-Blocker Heart Attack Trial Research Group. A randomized trial of propranolol in patients with acute myocardial infarction. I. Mortality results. FAMA 1982;247:1707-14

4 Olsson G, Rehnqvist N, Sjögren A, Erhardt L, Lundman T. Long-term treatment with metoprolol after myocardial infarction. Effect on 3 year mortality and morbidity. Foumal of the American College of Cardiologv 1985;5:1428-37.

5 Weinstein MC, Fineberg HV, Elstein AS, et al. Clinical decision analysis. Philadelphia: W B Saunders, 1980:191.

6 Lubsen J. Problems of objectives, evidence and inference in the MIAMI and Belfast trials. Eur Heart $\mathcal{F} 1985 ; 6: 216-24$.

7 Goldman L, Cook EF, Mitchell N, Flatley M, Sherman H, Cohn P. Pitfalls in the serial assessment of cardiac functional states: how a reduction of "ordinary" activity mav reduce the apparent degree of cardiac compromise and give a misleading impression of improvement. 7 Chronic Dis degree of cardiac

8 Olsson G, Hjemdahl P, Rehnqvist N. Rebound phenomena following gradual withdrawal of chronic metoprolol treatment in patients with ischemic heart disease. Am Heart $\mathcal{f}$ 1984;108: 454-62.

9 Dixon WJ, ed. BMDP statistical software. Berkley: University of California Press, 1985:359

(Accepted 24 April 1986) 